\title{
Evolving Concepts: How Diet and the Intestinal Microbiome Act as Modulators of Breast Malignancy
}

\author{
Iuliana Shapira, ${ }^{1}$ Keith Sultan, ${ }^{2}$ Annette Lee, ${ }^{3}$ and Emanuela Taioli ${ }^{4}$ \\ ${ }^{1}$ Monter Cancer Center, Don Monti Division of Oncology and Division of Hematology, Hofstra North Shore Long Island Jewish \\ School of Medicine, 450 Lakeville Road, Lake Success, NY 11042, USA \\ ${ }^{2}$ Hofstra North Shore Long Island Jewish School of Medicine, Division of Gastroenterology, Hepatology and Nutrition, \\ North Shore University Hospital, 300 Community Drive, Manhasset, NY 11030, USA \\ ${ }^{3}$ Feinstein Institute for Medical Research, Robert S. Boas Center for Genomics and Human Genetics and Elmezzi Graduate School of \\ Molecular Medicine, Hofstra North Shore Long Island Jewish School of Medicine, 350 Community Drive, Manhasset, NY 11030, USA \\ ${ }^{4}$ Population Health-Hofstra North Shore-LIJ School of Medicine and North Shore/LIJ Health System, 175 Community Drive, \\ Room 203, Great Neck, NY 11021, USA
}

Correspondence should be addressed to Keith Sultan; ksultan@nshs.edu

Received 30 July 2013; Accepted 25 August 2013

Academic Editors: B. B. Patel and D. Peng

Copyright (c) 2013 Iuliana Shapira et al. This is an open access article distributed under the Creative Commons Attribution License, which permits unrestricted use, distribution, and reproduction in any medium, provided the original work is properly cited.

\begin{abstract}
The intestinal microbiome plays an important role in human physiology. Next-generation sequencing technologies, knockout and gnotobiotic mouse models, fecal transplant data and epidemiologic studies have accelerated our understanding of microbiome abnormalities seen in immune diseases and malignancies. Dysbiosis is the disturbed microbiome ecology secondary to external pressures such as host diseases, medications, diet and genetic conditions often leading to abnormalities of the host immune system. Specifically dysbiosis has been shown to lower circulating lymphocytes, and increase neutrophil to lymphocyte ratio, a finding which has been associated with a decreased survival in women with breast cancers. Dysbiosis also plays a role in the recycling of estrogens via the entero-hepatic circulation, increasing estrogenic potency in the host, which is another leading cause of breast malignancy. Non-modifiable factors such as age and genetic mutations disrupt the microbiome, but modifiable factors such as diet may also lead to profound disruptions as well. A better understanding of dietary factors and how they disrupt the microbiome may lead to beneficial nutritional interventions for breast cancer patients.
\end{abstract}

\section{Introduction}

The human digestive tract is known to host trillions of microbes collectively called the intestinal microbiota [1-4]. A commensally, mutually beneficial relationship exists between the human host and these microbiota. The host's digestive tract provides the nutrient niche for the microbiota, while the microbiota protects against pathogens, helps in the development of the immune system, aids in nutrient reclamation from food by fermenting indigestible fiber to short chain fatty acids, produces essential amino acids and vitamins, helps in the absorption of minerals, and aids the breakdown of dietary toxins and carcinogens $[1-3,5]$. The intestinal microbiota also helps the growth and differentiation of enterocytes and colonocytes, thus maintaining the intestinal barrier against potential pathogens [6].

\section{Origin of Microbiome}

The intestinal microbiota is maternally inherited at birth as the newborn is delivered through the vaginal canal [7-9]. Later in development, factors both dependent on host choices such as diet and independent of host choices such as genetics and age modify the intestinal microbiota [10].

Insights into the dynamic structure of intestinal microbiota have become possible with the advent of nextgeneration sequencing technologies; such technologies are able to fully characterize the polymorphism of bacterial communities inhabiting the human intestines using bacterial $16 \mathrm{~S}$ RNA ribosomal sequences [11-13]. This approach showed that the major phylums in adults are Firmicutes and Bacteroidetes representing over $80 \%$ of the colorectal intestinal microbiota. Minor phylums such as Verrucomicrobia, Actinobacteria, 

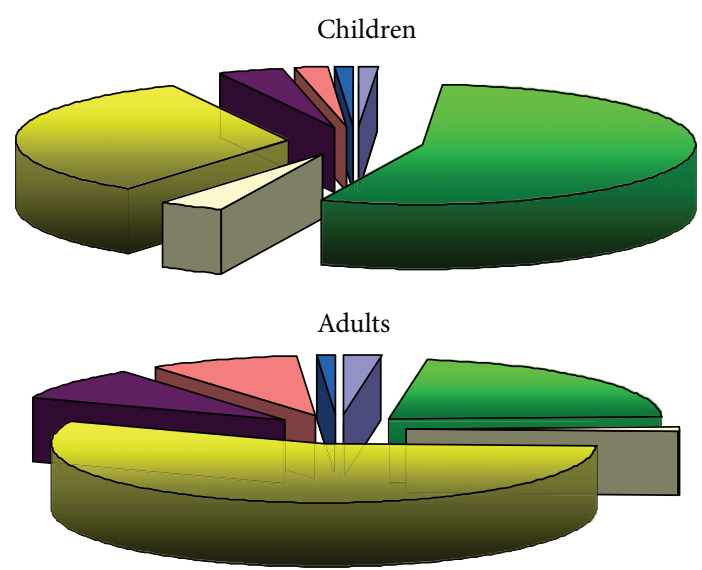

Elderly
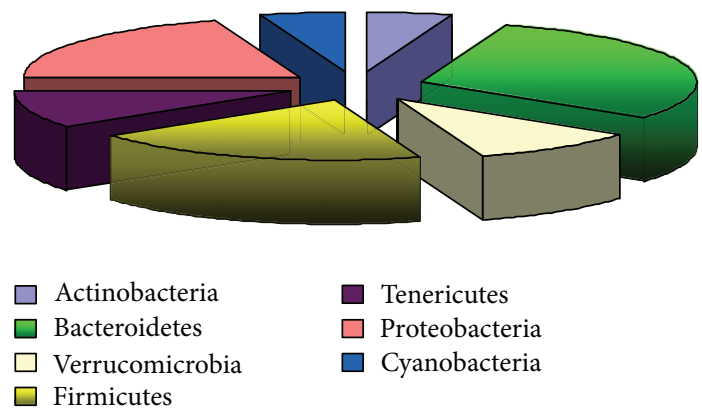

FIGURE 1: Major phylums in children, adults, and elderly detected by pyrosequencing of $16 S$ ribosomal RNA genes $[15,16]$.

Proteobacteria, Tenericutes, and Cyanobacteria represent the remaining $20 \%$ of the colon microbiota [14] (Figure 1).

The ratio of Firmicutes to Bacteroidetes changes with age. Newborns and infants have more Bacteroidetes; in adults Firmicutes are the predominant intestinal microbiome phylum, and in the elderly more Bacteroides and increased proportion of the minor phylum Proteobacteria are observed [10]. Major species associates with respective phylums are described in Table 1.

\section{Host Influence on the Microbiome}

Environmental and external factors may act on the composition of the microbiome. The term dysbiosis defines the disturbed microbiome ecology which may be secondary to external factors such as disease, medications, and diet as well as to nonmodifiable genetic conditions [18]. Knocking down genes of the immune system may lead to profound modifications in the intestinal microbiome and to predisposition to diseases of the immune system as well as cancer [19-21]. Animal models of fecal transplant of "dysbiotic" microbiome have been shown to alter the structure of recipient microbiome and to induce the development of the same immune disease that was initially seen in the genetically altered animal [19-22].

In general, several studies have shown that the microbiome structure suffers if genetic defects interfere with the normal development of the immune system of the animal [23-31]. Table 2 provides a summary of the current knowledge of how defects in the genetic factors that regulate the development of the immune system stunt the structure of the intestinal microbiome.

Human research has shown that patients with mutations in Crohn's disease genes such as nucleotide binding oligomerization domain 2 (NOD2) [33] and autophagy related protein 16L-1 (ATG16L1) [34] have decreased numbers of the Firmicutes species of bacteria Faecalibacterium prausnitzii and Roseburia intestinalis in their ileum [35]. This decrease in commensal bacteria is associated with a proportional increase in the pathogenic adherent invasive Escherichia coli and Salmonella typhimurium [36, 37]. The inability of Faecalibacterium and Roseburia to survive in the intestinal microbiome of patients with Crohn's disease deprives these patients of bacteria which produce short chain fatty acids (SCFA) used as nutrition and energy for colonocytes [38]. Decreased SCFA leads to increased colonocyte death, increased cell turnover and may explain in part the 3.2-fold higher lifetime risk of colorectal cancer observed in Crohn's when compared to general population $[39,40]$.

\section{Diet, Microbiome, Phytoestrogens, and Breast Cancer}

Fiber represents the indigestible portions of plant cell walls and may be either soluble or insoluble. The insoluble fibers, such as lignins, cellulose, dextrins, waxes, and chitins are not fermented by the human commensal microbiota. Soluble fiber such as inulin, arabinoxylans, pectins, beta-glucans, amylase resistant starches, fructans, and lignans are fermented by the intestinal microbiota into short chain fatty acids [41]. Lignans are substances found in whole grains, soy, fruits, and vegetables, while inulin, arabinoxylans and oligofructose are fibers found in artichoke, onion, and banana. Pectins and fructans are found predominantly in fruits [42]. Beta-glucans are soluble fibers found in mushrooms and amylase-resistant starches are found in beans and chickpeas [43-53].

The presence of high concentrations of soluble fiber in the distal ileum and colon favors the growth and maintenance of beneficial Bifidobacterium (from Actinobacteria phylum) the anti-inflammatory Faecalibacterium prausnitzii (a Firmicute) as well as commensal species from Bacteroidetes phylum [54, 55]. By-products of bacterial fermentation of soluble fibers are short chain fatty acids (acetate, propionate, and butyrate), the preferred source of energy for colonocytes [56].

In one study, fourteen healthy volunteers consumed for 2 weeks a high fiber diet (19 grams/day) followed by 2 weeks of a low fiber diet (under 5 grams/day). The microbiome was analyzed and Faecalibacterium prausnitzii, Roseburia intestinalis (from Firmicute phylum) were quantified by $16 \mathrm{~S}$ ribosomal tagged probes by fluorescent in situ hybridization concomitantly with the quantity of short chain fatty acids (SCFA) per gram of dry fecal weight [57]. The low fiber diet was associated with a statistically significant $80 \%$ reduction in Faecalibacterium prausnitzii, Roseburia intestinalis, and SCFA $(P<0.001)$. At 2 weeks, the fiber rich diet increased ten-folds 
TABLE 1: The composition of human colonic microbiome: phylums and selected major species belonging to each phylum [14, 17].

\begin{tabular}{ll}
\hline Phylum & Species \\
\hline Actinobacteria & Bifidobacterium \\
Bacteroidetes & Bacteroides, Prevotella, Porphyromonas \\
Verrucomicrobia & Akkermansia \\
Firmicutes & Clostridium, Faecalibacterium, Ruminococcus, Roseburia, Veillonella, Staphylococcus, Streptococcus, segmented \\
Tenericutes & Erysipelotrichaceae \\
Proteobacteria & Citrobacter, Enterobacter, E. coli, Shigella, Klebsiella, Hemophilus, Sphingomonas \\
Cyanobacteria & Unclassified YS2 \\
\hline
\end{tabular}

TABLE 2: The influence of host genes on the structure of the intestinal microbiome in gnotobiotic rodents [32].

\begin{tabular}{|c|c|c|c|c|}
\hline Mouse model & $\begin{array}{c}\text { Phenotype/microbiome in } \\
\text { mouse model }\end{array}$ & $\begin{array}{l}\text { Systemic manifestation of } \\
\text { abnormal microbiome in mice }\end{array}$ & $\begin{array}{l}\text { Results of fecal transplant to wild } \\
\text { type animal }\end{array}$ & References \\
\hline Rag2-knockout & $\begin{array}{l}\text { No functional B and T } \\
\text { cells/inflammatory colitis }\end{array}$ & Recurrent infections & Inflammatory colitis & {$[23,24]$} \\
\hline Tbx21-knockout & $\begin{array}{l}\text { No functional Th1 cells/Crohn's } \\
\text { disease, colitis }\end{array}$ & $\begin{array}{l}\text { Asthma, autoimmune disease, } \\
\text { and various malignancies }\end{array}$ & $\begin{array}{l}\text { Crohn's disease, colitis, asthma, and } \\
\text { autoimmune disease }\end{array}$ & {$[25]$} \\
\hline TLR5-knockout & No flagellin receptor & $\begin{array}{l}\text { Metabolic syndrome: insulin } \\
\text { resistance, hyperlipidemia, fat } \\
\text { deposition on omentum, and } \\
\text { atherosclerosis }\end{array}$ & $\begin{array}{l}\text { Metabolic syndrome: insulin } \\
\text { resistance, hyperlipidemia, fat } \\
\text { deposition on omentum, and } \\
\text { atherosclerosis }\end{array}$ & {$[26]$} \\
\hline SHP-1 mutation & $\begin{array}{l}\text { No T, B cells and no } \\
\text { immunoglobulins/colitis }\end{array}$ & $\begin{array}{l}\text { Autoimmune disease, alopecia, } \\
\text { glomerulonephritis, } \\
\text { pneumonitis, colitis, and paws } \\
\text { inflammation triggered by } \\
\text { microbiota }\end{array}$ & $\begin{array}{l}\text { Colitis alopecia, } \\
\text { glomerulonephritis, and } \\
\text { pneumonitis }\end{array}$ & {$[27,28]$} \\
\hline $\begin{array}{l}\text { NLR-P3 gene } \\
\text { mutation }\end{array}$ & $\begin{array}{l}\text { Cold urticaria inflammatory } \\
\text { disease, dysbiosis }\end{array}$ & $\begin{array}{l}\text { Dysbiosis, cold urticaria } \\
\text { inflammatory disease }\end{array}$ & $\begin{array}{l}\text { Colitis, cold urticaria inflammatory } \\
\text { disease }\end{array}$ & {$[29]$} \\
\hline NOD-2 mutation & $\begin{array}{l}\text { Abnormal innate immune } \\
\text { response }\end{array}$ & Various adenocarcinomas & Crohn's disease, dysbiosis & {$[30,31]$} \\
\hline
\end{tabular}

Rag2: recombination activating gene 2.

NLR-P3: nucleotide binding oligomerization domain (NOD) like receptors P3.

Tbx21: T cell specific T-box transcription factor (crucial transcription factor for TH1 cells); TLR-5: toll-like receptor 5.

SHP-1: Src homology region 2 domain-containing phosphatase-1.

NOD-2: nucleotide binding oligomerization domain 2.

the quantity of SCFA and of both F. prausnitzii and Roseburia $(P<0.01)$ [57].

The promotion of growth of Firmicutes and Bacteroidetes within the intestinal microbiome by dietary fibers has another important effect: these bacteria are able to metabolize dietary lignans into the potent phytoestrogens enterodiol (END) and its oxidation product enterolactone (ENL), which are then readily absorbed into bloodstream $[58,59]$.

Antibiotic use influences the bioavailability of enterolactone due to disruptions in the intestinal microbiome [60].

Unlike estrogen, high blood levels of phytoestrogens have been shown to be inversely associated with risk of breast cancer in epidemiologic studies $[61,62]$. In a population based case-control study of over 6,000 women, consumption of lignans three times per week was associated with a $50 \%$ reduction in breast cancer risk in premenopausal women. Notably, this benefit was also seen in overweight and obese women [63].
Research on more than 35,000 women participants in the UK Women's Cohort Study showed that premenopausal women who ate most of their fiber from whole grains (at least 13 grams per day of whole grain fiber) and 30 grams per day of total fiber had $50 \%$ less breast cancer. If the majority of soluble fiber came from fruits rather than whole grains the protection from breast cancer was slightly lower $35 \%$ for those women who ate 30 grams of fiber compared to those who ate only 2 grams of fiber daily [64].

The benefit of high fiber diets extends to postmenopausal women, despite the fact that with age the intestinal microbiota ratio of Firmicutes to Bacteroidetes phylums changes in an unfavourable direction [10].

A study of over 51,000 postmenopausal women followed over more than 8 years showed that women who consumed 30 grams or more of fiber from fruit and whole grains had 34\% less breast cancer than those who consumed less quantities 
of those items. Notably, lignan fiber seemed to be more protective than fruit and vegetable fibers [65].

In another study, premenopausal women at risk for breast cancer because of benign breast disease (such as ductal hyperplasia, lobular hyperplasia, radial scar) were asked to undergo a baseline periareolar fine needle aspiration (RPFNA) and were then followed on a diet which included daily plant lignans (intervention) for one year. Serum enterolactone was measured before and after the intervention. After intervention serum enterolactone increased ninefold from the baseline. After one year, a repeated RPFNA showed atypia in only half of the women treated with diets rich in lignans in whom the serum enterolactones increased ninefold from baseline levels [66].

A Finnish case-control study also looked at serum levels of enterolactone and their association with breast cancer. Women with the highest dietary intake on lignans (at least two slices of rye bread per day) were in the highest quintile of serum enterolactone $(54 \mathrm{nmol} / \mathrm{L})$ while with the lowest consumption were in the lowest quintile $(3 \mathrm{nmol} / \mathrm{L})$. After eight years of followup, women in the highest quintile of enterolactone had $62 \%$ less breast cancer diagnosed compared to the lowest quintile [67].

In a study of more than 300 women diagnosed with breast cancer, serum enterolactone was used to quantify the amount of dietary lignans consumed. At a median followup of 276 months there was 30\% decrease in breast cancer specific mortality in patients with enterolactone levels more than $10 \mathrm{nmol} / \mathrm{L}$ [68].

A recent meta-analysis of serum enterolactones and breast cancer showed a protective effect for breast cancer for women with serum levels in the highest quartile compared to the lowest (meta-OR: 0.72; 95\% CI: 0.55-0.88) [69]. The effect was more pronounced in postmenopausal women [69].

Serum enterolactone, a product of microbiome fermentation of dietary lignans, appear to have protective effects in breast cancer patients and in breast cancer prevention.

\section{Diet, Microbiome, Estrogens, and Breast Cancer}

Saturated fats are the source of cholesterol used by the ovaries for estrogen synthesis. In postmenopausal women the adipose tissue, adrenal glands, and other organs transform circulating androgens into estrogens using the aromatase enzymes [70]. In the blood, estrogens circulate either bound to proteins or free. The liver inactivates estrogens by conjugation, that is, sulfonation, methylation, and glucuronidation reactions; conjugated estrogens are then finally excreted with bile acids and are transported into the intestinal lumen [71]. Once in the intestinal lumen, the fate of these conjugated estrogens depends on the composition of the intestinal microbiota present in the host. Individuals with an intestinal microbiome capable of deconjugating estrogens will reabsorb the free estrogen via the enterohepatic circulation, increasing the estrogenic potency in the host. Those with an intestinal microbiome less favorable to deconjugation will promote estrogen excretion in feces [72]. Thus diet plays an important role in creating the microbiome environment that deconjugates estrogens or is indifferent to conjugated estrogens.

Diets rich in fats and red meat promote the production and excretion of bile acids necessary for fat digestion and absorption. Commensal bacteria then break down these bile acids into deoxycholic and lithocholic acids, metabolites that favor the growth of Proteobacteria species such as E. coli, Klebsiella, Enterobacter, and Citrobacter and are detrimental to certain species of Firmicutes and Bacteroidetes in the intestinal microbiota. This process in turn produces a dysbiotic state [73] that favors the growth of E. coli from Proteobacteria phylum, an organism that is able to produce potent beta-glucuronidases [74], deconjugating estrogens in the intestinal lumen and thus contributing to the higher estrogenic burden of the host [75]. A direct relationship between higher circulating estrogen levels and the increased risk of postmenopausal women developing breast cancer has been extensively reported in the literature [76].

\section{The Microbiome's Role in Obesity and Breast Cancer}

Diet-induced obesity changes the balance of Firmicutes to Bacteroidetes phylums. Studies in twins, of which one is obese, the other nonobese, have shown smaller Bacteroidetes phylums and more Firmicutes in the obese twin as compared to the lean twin [77, 78]. Notably, the ratio of Bacteroidetes increases at the expense of Firmicutes when the obese individual loses weight or after gastric bypass surgery [79]. It is unknown whether the change in proportion of Firmicutes to Bacteroidetes, allowing for the growth of detrimental species in the microbiome, is merely an effect of obesity or a cofactor that promotes obesity. It has been speculated that intestinal dysbiosis (perpetuated by atherogenic, western diet) and not merely high caloric intake is a main cofactor in the obesity epidemic in the Western world [80]. This concomitant presence of dysbiosis and obesity, and the resulting increased circulating estrogen levels, may synergistically contribute to the $20 \%$ higher risk of breast cancer seen among women with a BMI greater than $30 \mathrm{~kg} / \mathrm{m}^{2}$, as compared to normal weight controls [81].

\section{The Microbiome's Role in Immune Modulation and Breast Cancer}

Much of what we know about the symbiotic interaction between the intestinal microbiome and systemic immune system development has come from the study of germ-free (knows as gnotobiotic) rodents. Lack of intestinal microbiota in gnotobiotic rodents decreases the size of the small and large intestine Peyer's patches of the spleen and also affects distant immune organs. The size of the pancreas and the number of beta-cells are decreased [82], and the hypothalamic-pituitaryadrenal axis stress response is also altered [83]. The lack of a microbiome decreases the number and function of neutrophils due to decreased microbiota-derived peptidoglycans responsible for serum and bone marrow neutrophil function [84]. 

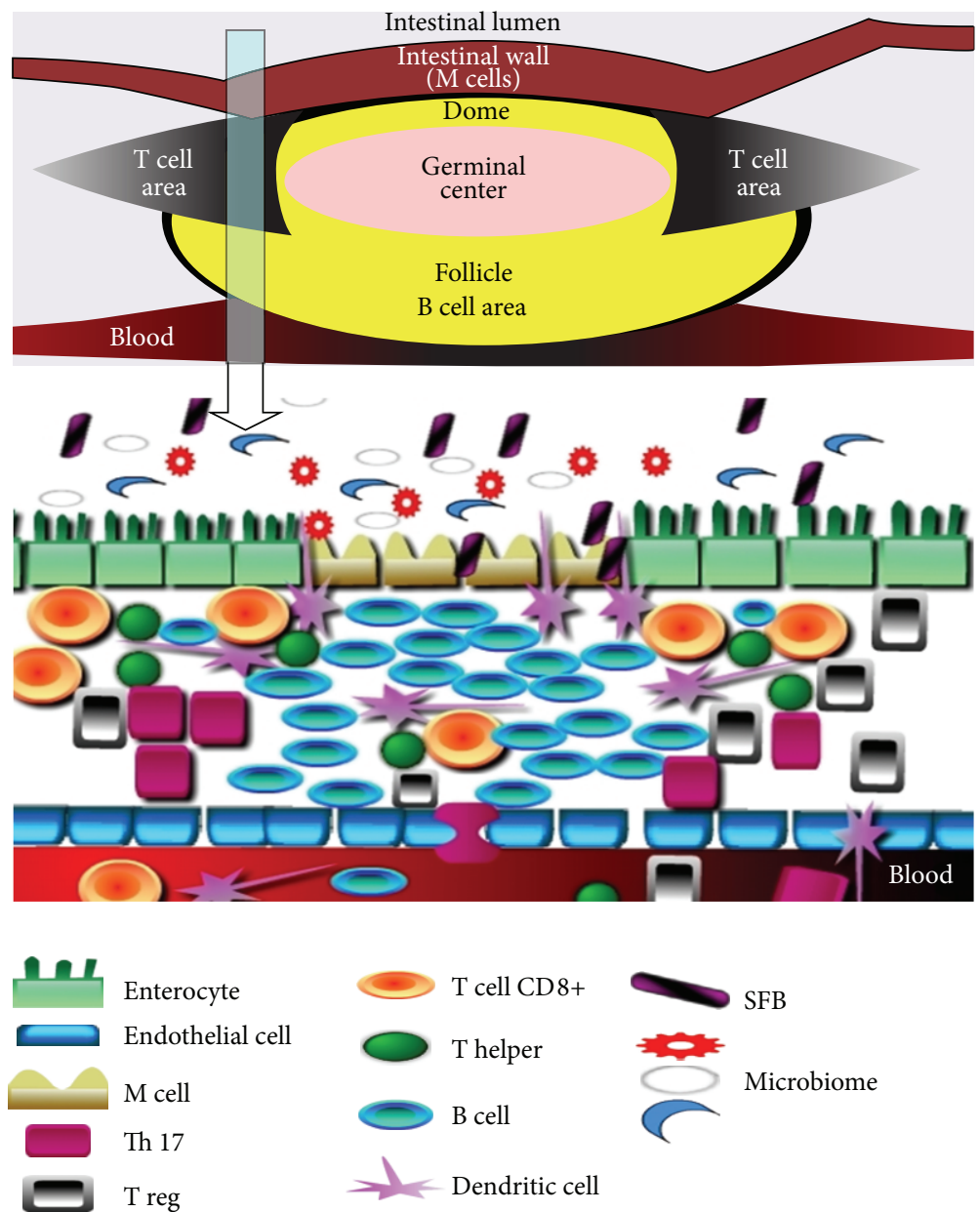

FIGURE 2: Schematic representation of Peyer's patch organization (also known as gut-associated lymphoid tissue-GALT) shows that the bulk of the tissue is made up by B cells organized in a large and highly active domed follicle. T cells occupy the areas between the follicles. The antigen enters across a specialized epithelium made up of so-called multifenestrated $(\mathrm{M})$ cells. The germinal center is located in the center of the follicle. Cross-section through the Peyer's patch shows the types of cells and the interactions between the cells of the immune system and the microbiome. M cells: multifenestrated cells; Th-17: T cell helper 17; Treg: T regulatory cells; T cells CD8+: effectors T cells; T helper: naïve CD4+ T cells; B cell; SFB: segmented filamentous bacteria.

The colonization of gnotobiotic rodents with known strains of human microbiome allows measuring the effects of known bacterial species on the immune system development.

Normal microbiome contributes to maturation of effector CD8+ T cells (known as killer $\mathrm{T}$ cells) via contact with Sphingomonas species (of Proteobacteria phylum) [85]. Inflammation decreases the proportion of Sphingomonas in the Proteobacteria phylum and prevents proper development of CD8+ antitumor cytotoxic T cells $[86,87]$. CD8+ T cells are the most potent immune cells capable of eliminating foreign antigens and breast tumor cells [88].

$\mathrm{T}$ cell differentiation takes place in the thymus from 12 weeks of gestation until the thymus regresses through involution by 9 months of age [89]. The role of thymus in immune reconstruction is replaced in part by the interactions between the trillions of organisms in the microbiome and cells of the immune system $[89,90]$. These interactions take place with the help of multifenestrated epithelial cells ( $M$ cells) lining the Peyer's patches (Figure 2). Dendritic cells in the Peyer's patches sample via direct contact the microbial contents of the intestines and adapt the immune responses to the antigenic load. Segmented filamentous bacteria (SFB) have direct contact with dendritic cells in the Peyer's patches. They are necessary and sufficient to contribute to the maturation of CD8+ effector cytotoxic T cells and CD4+ helper cells [91] (Figure 2). Table 3 summarizes the contribution of different phylums and species in the microbiome to the maturation of the immune system.

It was previously noted that diets rich in fats and red meats result in dysbiosis, favoring the growth of Proteobacteria phylum (species such as E. coli, Klebsiella, Enterobacter, and Citrobacter) and Fusobacterium nucleatum [103, 104] and impacting in a negative way certain species of Firmicutes and Bacteroidetes [73]. Notably, Fusobacterium nucleatum species are able to kill maturing lymphocytes via $\mathrm{M}$ cells in the Peyer's patches via direct contact, lowering the number of circulating systemic lymphocytes [92, 105] (Figure 2). 
TABLE 3: Microbiome role in maturation of the immune system and involvement in cancer.

\begin{tabular}{|c|c|c|c|}
\hline Microbiome components & Immune cell development & Role in cancer & References \\
\hline Firmicutes phylum: Fusobacterium nucleatum & Direct killing of lymphocytes; & $\begin{array}{l}\text { Promotes metastasis and } \\
\text { tumor growth }\end{array}$ & {$[92]$} \\
\hline $\begin{array}{l}\text { Proteobacteria: E. coli, Citrobacter, Enterobacter, } \\
\text { Shigella, Klebsiella, and Hemophilus }\end{array}$ & Promotes TH17 & $\begin{array}{l}\text { Promotes cancer progression } \\
\text { and metastasis }\end{array}$ & {$[93]$} \\
\hline Archea phylum: Eubacterium rectale & $\begin{array}{l}\text { IL- } 6 \text { production by intestinal } \\
\text { inflammatory dendritic cells }\end{array}$ & $\begin{array}{l}\text { Promotes cancer progression } \\
\text { and metastasis }\end{array}$ & {$[94]$} \\
\hline $\begin{array}{l}\text { Proteobacteria phylum: Sphingomonas species, } \\
\text { Clostridium cluster IV-XIVa }\end{array}$ & CD8+ T cells & Anti cancer activities & $\begin{array}{c}{[91,95]} \\
{[22,96-101]}\end{array}$ \\
\hline Actinobacterium phylum: Bifidobacterium & Th1 noninflammatory & $\begin{array}{l}\text { Protects against inflammation } \\
\text { and cancer }\end{array}$ & {$[102]$} \\
\hline
\end{tabular}

An intestinal microbiome that destroys lymphocytes may influence the outcomes of cancer. Patients with a lower number of systemic lymphocytes at diagnosis appear to have poorer cancer-related outcomes. Studies show that the ratio of neutrophils to lymphocytes (calculated as neutrophil count divided by lymphocyte count) at diagnosis predicts longterm cancer outcome, with higher ratios predicting worse outcomes independently of patients' age or stage at diagnosis [106-109].

In a study of early stage breast cancer (stages I, II, and III) a neutrophil-to-lymphocyte ratio of more than 2.5 was associated with 4-fold risk of disease relapse at 10 years compared to patients with a ratio lower than 2.5 regardless of stage or age at diagnosis $(P<0.001)$ [110]. A retrospective study of 316 breast cancer patients showed that a neutrophilto-lymphocyte ratio of more than 3.3 at diagnosis had a $44 \%$ higher risk of death within 5 years of cancer diagnosis compared to those with a ratio less than $1.8(P<0.0001)$ [111].

In BIG-02-98 study of more than 2000 patients with node positive breast cancer more than $50 \%$ infiltration of tumor stroma with lymphocytes was associated with reduced risk of breast cancer relapse and death. For each additional 10\% increase in percentage of lymphocytes the risk of relapse was $17 \%$ lower and risk of death was $27 \%$ lower independent of stage at diagnosis and patients' age $(P<0.0001)[112]$.

Most chemotherapy decreases tumor burden by 1-2 logs. The decrease is followed by immune recognition of tumor antigens, with the desirable response being that the rest of the tumor burden is dealt with by the patient's own immune system [113]. CD8+ T cells are the most potent immune cells capable of eliminating foreign antigens and breast tumor cells [88]. A normal microbiome contributes to maturation of effector CD8+ T cells (known as killer T cells) via contact with Sphingomonas species (of Proteobacteria phylum) [85]. Inflammation decreases the proportion of Sphingomonas in the Proteobacteria phylum and prevents proper development of CD8+ antitumor cytotoxic T cells detected in the peripheral blood $[86,87]$.

Research correlating the number of CD8+ effector T cells infiltrating breast cancer tumors with patients survival shows that patients with higher numbers of effector $\mathrm{T}$ cells in their breast tumors have better chance of being successfully treated for their disease or being long-term survivors than those without these immune cells. In a study of over 1,300 patients followed for over 10 years, patients whose breast tumors had more than 24 of CD8+ cells per high power field of the tumor had better breast cancer specific survival, $75 \%$ versus $45 \%$ $(P<0.001)$, than those having fewer than five [114]. In over 170 triple negative breast cancer patients followed over 8 years after the diagnosis, patients with more lymphocytes infiltrating their tumors more than $36 / \mathrm{mm}^{2}$ were associated with a $60 \%$ recurrence-free survival at 8 years versus $20 \%$ in patients with fewer than $20 / \mathrm{mm}^{2}(P<0.0019)$ [115].

\section{Conclusion}

The incidence of breast cancer around the world is vastly different in the USA and Western Europe compared to Asia and Africa. In the industrialized world, the incidence is around 120 women per 100,000 individuals per year; in the less developed parts of the world it is 17 per 100,000 [116]. The western born children of those immigrants, however, have the same incidences of breast cancer as their western compatriots, rather than that of their ancestors. This occurs despite the obvious fact that their genes pool does not significantly change over just one generation [117]. The major change that occurred is environmental; diet and the resulting microbiome changes appear to play a major role among the possible environmental factors [118]. Advances in understanding of our diet, our microbiome, and the complex interactions between the two, hold the potential to modify not just the course of digestive diseases but also of disorders such as breast cancer. It is hoped that a deeper understanding of this world within us can point the way towards evidence based dietary therapies to decrease the risk of developing breast cancer as well as improve the outcomes of those already diagnosed.

\section{Acknowledgments}

This work was supported in part by the National Cancer Institute grant 2U10CA035279 and by the philanthropic donations from Betta and Jerry Clair, Mrs. and Mr. Henry Gabbay, Dr. and Mrs. Teitelbaum, Manhasset Women's Coalition Against Breast Cancer, Moms Who Kick, and Partner's Council for Women's Health. 


\section{References}

[1] I. Sekirov, N. Gill, M. Jogova et al., "Salmonella SPI-1-mediated neutrophil recruitment during enteric colitis is associated with reduction and alteration in intestinal microbiota," Gut Microbes, vol. 1, no. 1, pp. 30-41, 2010

[2] A. J. Macpherson and N. L. Harris, "Interactions between commensal intestinal bacteria and the immune system," Nature Reviews Immunology, vol. 4, no. 6, pp. 478-485, 2004.

[3] L. V. Hooper and J. I. Gordon, "Commensal host-bacterial relationships in the gut," Science, vol. 292, no. 5519, pp. 1115-1118, 2001.

[4] L. V. Hooper, M. H. Wong, A. Thelin, L. Hansson, P. G. Falk, and J. I. Gordon, "Molecular analysis of commensal host-microbial relationships in the intestine," Science, vol. 291, no. 5505, pp. 881$884,2001$.

[5] F. Bäckhed, R. E. Ley, J. L. Sonnenburg, D. A. Peterson, and J. I. Gordon, "Host-bacterial mutualism in the human intestine," Science, vol. 307, no. 5717, pp. 1915-1920, 2005.

[6] C. A. Allen and A. G. Torres, "Host-microbe communication within the GI tract," Advances in Experimental Medicine and Biology, vol. 635, pp. 93-101, 2008.

[7] R. E. Ley, M. Hamady, C. Lozupone et al., "Evolution of mammals and their gut microbes," Science, vol. 320, no. 5883, pp. 1647-1651, 2008.

[8] H. Ochman, M. Worobey, C.-H. Kuo et al., "Evolutionary relationships of wild hominids recapitulated by gut microbial communities," PLoS Biology, vol. 8, no. 11, Article ID e1000546, 2010.

[9] Y. Li, A. I. Ismail, Y. Ge, M. Tellez, and W. Sohn, "Similarity of bacterial populations in saliva from African-American motherchild dyads," Journal of Clinical Microbiology, vol. 45, no. 9, pp. 3082-3085, 2007

[10] D. Mariat, O. Firmesse, F. Levenez et al., "The firmicutes/bacteroidetes ratio of the human microbiota changes with age," BMC Microbiology, vol. 9, article 123, 2009.

[11] S. Vaishnava, M. Yamamoto, K. M. Severson et al., "The antibacterial lectin RegIII $\gamma$ promotes the spatial segregation of microbiota and host in the intestine," Science, vol. 334, no. 6053, pp. 255-258, 2011.

[12] S. Schloissnig, M. Arumugam, S. Sunagawa et al., "Genomic variation landscape of the human gut microbiome," Nature, vol. 493, no. 7430, pp. 45-50, 2012.

[13] G. M. Weinstock, "Genomic approaches to studying the human microbiota," Nature, vol. 489, no. 7415, pp. 250-256, 2012.

[14] A. Lin, E. M. Bik, E. K. Costello et al., "Distinct distal gut microbiome diversity and composition in healthy children from bangladesh and the United States," PLoS ONE, vol. 8, no. 1, Article ID e53838, 2013.

[15] T. Z. DeSantis Jr., P. Hugenholtz, K. Keller et al., "NAST: a multiple sequence alignment server for comparative analysis of 16S rRNA genes," Nucleic Acids Research, vol. 34, pp. W394W399, 2006.

[16] T. Z. DeSantis, P. Hugenholtz, N. Larsen et al., "Greengenes, a chimera-checked $16 \mathrm{~S}$ rRNA gene database and workbench compatible with ARB," Applied and Environmental Microbiology, vol. 72, no. 7, pp. 5069-5072, 2006.

[17] P. J. Turnbaugh, V. K. Ridaura, J. J. Faith, F. E. Rey, R. Knight, and J. I. Gordon, "The effect of diet on the human gut microbiome: a metagenomic analysis in humanized gnotobiotic mice," Science Translational Medicine, vol. 1, no. 6, p. 6ra14, 2009.
[18] I. Cho and M. J. Blaser, "The human microbiome: at the interface of health and disease," Nature Reviews Genetics, vol. 13, no. 4, pp. 260-270, 2012.

[19] M. B. Geuking, J. Cahenzli, M. A. E. Lawson et al., "Intestinal bacterial colonization induces mutualistic regulatory $\mathrm{T}$ cell responses," Immunity, vol. 34, no. 5, pp. 794-806, 2011.

[20] A. J. Macpherson, M. B. Geuking, and K. D. McCoy, "Innate and adaptive immunity in host-microbiota mutualism," Frontiers in Bioscience, vol. 4, pp. 685-698, 2012.

[21] A. Y. Rudensky and A. V. Chervonsky, "A narrow circle of mutual friends," Immunity, vol. 34, no. 5, pp. 697-699, 2011.

[22] M. B. Geuking, K. D. McCoy, and A. J. Macpherson, "The continuum of intestinal CD4+ $\mathrm{T}$ cell adaptations in hostmicrobial mutualism," Gut Microbes, vol. 2, no. 6, pp. 353-357, 2011.

[23] W. S. Garrett and L. H. Glimcher, "T-bet-/- RAG2-/- ulcerative colitis: the role of T-bet as a peacekeeper of host-commensal relationships," Cytokine, vol. 48, no. 1-2, pp. 144-147, 2009.

[24] N. Powell, A. W. Walker, E. Stolarczyk et al., "The transcription factor T-bet regulates intestinal inflammation mediated by interleukin-7 receptor+ innate lymphoid cells," Immunity, vol. 37, no. 4, pp. 674-684, 2012.

[25] W. S. Garrett, G. M. Lord, S. Punit et al., "Communicable ulcerative colitis induced by T-bet deficiency in the innate immune system," Cell, vol. 131, no. 1, pp. 33-45, 2007.

[26] M. Vijay-Kumar, J. D. Aitken, F. A. Carvalho et al., "Metabolie syndrome and altered gut microbiota in mice lacking toll-like receptor 5," Science, vol. 328, no. 5975, pp. 228-231, 2010.

[27] G. P. Christophi, C. A. Hudson, R. C. Gruber et al., "SHP1 deficiency and increased inflammatory gene expression in PBMCs of multiple sclerosis patients," Laboratory Investigation, vol. 88, no. 3, pp. 243-255, 2008.

[28] B. A. Croker, B. R. Lawson, S. Rutschmann et al., "Inflammation and autoimmunity caused by a SHP1 mutation depend on IL1, MyD88, and a microbial trigger," Proceedings of the National Academy of Sciences of the United States of America, vol. 105, no. 39, pp. 15028-15033, 2008.

[29] S. A. Hirota, J. Ng, A. Lueng et al., "NLRP3 inflammasome plays a key role in the regulation of intestinal homeostasis," Inflammatory Bowel Diseases, vol. 17, no. 6, pp. 1359-1372, 2011.

[30] Q. Pan, J. Mathison, C. Fearns et al., "MDP-induced interleukin$1 \beta$ processing requires Nod 2 and CIAS1/NALP3," Journal of Leukocyte Biology, vol. 82, no. 1, pp. 177-183, 2007.

[31] T. Tanabe, M. Chamaillard, Y. Ogura et al., "Regulatory regions and critical residues of NOD2 involved in muramyl dipeptide recognition," EMBO Journal, vol. 23, no. 7, pp. 1587-1597, 2004.

[32] L. V. Hooper, D. R. Littman, and A. J. Macpherson, "Interactions between the microbiota and the immune system," Science, vol. 336, no. 6086, pp. 1268-1273, 2012.

[33] Y.-G. Kim, M. H. Shaw, N. Warner et al., “Cutting Edge: Crohn’s disease-associated Nod2 mutation limits production of proinflammatory cytokines to protect the host from Enterococcus faecalis-induced lethality," Journal of Immunology, vol. 187, no. 6, pp. 2849-2852, 2011.

[34] T. S. Plantinga, L. A. B. Joosten, and M. G. Netea, "ATG16L1 polymorphisms are associated with NOD2-induced hyperinflammation," Autophagy, vol. 7, no. 9, pp. 1074-1075, 2011.

[35] D. N. Frank, C. E. Robertson, C. M. Hamm et al., "Disease phenotype and genotype are associated with shifts in intestinalassociated microbiota in inflammatory bowel diseases," Inflammatory Bowel Diseases, vol. 17, no. 1, pp. 179-184, 2011. 
[36] A. Kaser, S. Zeissig, and R. S. Blumberg, "Genes and environment: how will our concepts on the pathophysiology of IBD develop in the future?" Digestive Diseases, vol. 28, no. 3, pp. 395$405,2010$.

[37] S. E. Winter, P. Thiennimitr, M. G. Winter et al., "Gut inflammation provides a respiratory electron acceptor for Salmonella," Nature, vol. 467, no. 7314, pp. 426-429, 2010.

[38] K. Meijer, P. De Vos, and M. G. Priebe, "Butyrate and other short-chain fatty acids as modulators of immunity: what relevance for health?" Current Opinion in Clinical Nutrition and Metabolic Care, vol. 13, no. 6, pp. 715-721, 2010.

[39] Y. Yano, T. Matsui, H. Uno, F. Hirai, K. Futami, and A. Iwashita, "Risks and clinical features of colorectal cancer complicating Crohn's disease in Japanese patients," Journal of Gastroenterology and Hepatology, vol. 23, no. 11, pp. 1683-1688, 2008.

[40] J. J. Kovarik, W. Tillinger, J. Hofer et al., "Impaired antiinflammatory efficacy of n-butyrate in patients with IBD," European Journal of Clinical Investigation, vol. 41, no. 3, pp. 291298, 2011.

[41] D. L. Topping and P. M. Clifton, "Short-chain fatty acids and human colonic function: roles of resistant starch and nonstarch polysaccharides," Physiological Reviews, vol. 81, no. 3, pp. 10311064, 2001.

[42] N. M. Saarinen, A. I. Smeds, J. L. Penalvo, T. Nurmi, H. Adlercreutz, and S. Makela, "Flaxseed ingestion alters ratio of enterolactone enantiomers in human serum," Journal of Nutrition and Metabolism, vol. 2010, Article ID 403076, 5 pages, 2010.

[43] S. H. Albeituni and J. Yan, "The effects of beta-Glucans on dendritic cells and implications for cancer therapy," Anti-Cancer Agents in Medicinal Chemistry, vol. 13, no. 5, pp. 689-698, 2013.

[44] E. Aleem, "beta-Glucans and their applications in cancer therapy: focus on human studies," Anti-Cancer Agents in Medicinal Chemistry, vol. 13, no. 5, pp. 709-719, 2013.

[45] M. Driscoll, R. Hansen, C. Ding, D. E. Cramer, and J. Yan, "Therapeutic potential of various beta-glucan sources in conjunction with anti-tumor monoclonal antibody in cancer therapy," Cancer Biology \& Therapy, vol. 8, no. 3, pp. 218-225, 2009.

[46] K. Ito, Y. Masuda, Y. Yamasaki, Y. Yokota, and H. Nanba, "Maitake beta-glucan enhances granulopoiesis and mobilization of granulocytes by increasing G-CSF production and modulating CXCR4/SDF-1 expression," International Immunopharmacology, vol. 9, no. 10, pp. 1189-1196, 2009.

[47] Y. Masuda, M. Inoue, A. Miyata, S. Mizuno, and H. Nanba, "Maitake $\beta$-glucan enhances therapeutic effect and reduces myelosupression and nephrotoxicity of cisplatin in mice," International Immunopharmacology, vol. 9, no. 5, pp. 620-626, 2009.

[48] O. Rop, J. Mlcek, and T. Jurikova, "Beta-glucans in higher fungi and their health effects," Nutrition Reviews, vol. 67, no. 11, pp. 624-631, 2009.

[49] D. M.-Y. Sze and G. C.-F. Chan, "Supplements for immune enhancement in hematologic malignancies," Hematology, pp. 313-319, 2009.

[50] V. Vetvicka, A. Vashishta, S. Saraswat-Ohri, and J. Vetvickova, "Immunological effects of yeast- and mushroom-derived $\beta$ glucans," Journal of Medicinal Food, vol. 11, no. 4, pp. 615-622, 2008.

[51] K. Yamamoto, T. Kimura, A. Sugitachi, and N. Matsuura, "Anti-angiogenic and anti-metastatic effects of $\beta$-1,3-D-glucan purified from hanabiratake, Sparassis crispa," Biological and Pharmaceutical Bulletin, vol. 32, no. 2, pp. 259-263, 2009.
[52] T. J. Yoon, S. Koppula, and K. H. Lee, "The Effects of betaglucans on cancer metastasis," Anti-Cancer Agents in Medicinal Chemistry, vol. 13, no. 5, pp. 699-708, 2013.

[53] S. L. H. Williamson, A. Kartheuser, J. Coaker et al., "Intestinal tumorigenesis in the Apc1638N mouse treated with aspirin and resistant starch for up to 5 months," Carcinogenesis, vol. 20, no. 5, pp. 805-810, 1999.

[54] B. Hippe, J. Zwielehner, K. Liszt, C. Lassl, F. Unger, and A. G. Haslberger, "Quantification of butyryl CoA:acetate CoAtransferase genes reveals different butyrate production capacity in individuals according to diet and age," FEMS Microbiology Letters, vol. 316, no. 2, pp. 130-135, 2011.

[55] C. Ramirez-Farias, K. Slezak, Z. Fuller, A. Duncan, G. Holtrop, and P. Louis, "Effect of inulin on the human gut microbiota: stimulation of Bifidobacterium adolescentis and Faecalibacterium prausnitzii," British Journal of Nutrition, vol. 101, no. 4, pp. 541-550, 2009.

[56] D. R. Donohoe, N. Garge, X. Zhang et al., "The microbiome and butyrate regulate energy metabolism and autophagy in the mammalian colon," Cell Metabolism, vol. 13, no. 5, pp. 517-526, 2011.

[57] R. F. J. Benus, T. S. Van Der Werf, G. W. Welling et al., "Association between Faecalibacterium prausnitzii and dietary fibre in colonic fermentation in healthy human subjects," British Journal of Nutrition, vol. 104, no. 5, pp. 693-700, 2010.

[58] C.-Z. Wang, X.-Q. Ma, D.-H. Yang et al., "Production of enterodiol from defatted flaxseeds through biotransformation by human intestinal bacteria," BMC Microbiology, vol. 10, article $115,2010$.

[59] H. Adlercreutz, "Lignans and human health," Critical Reviews in Clinical Laboratory Sciences, vol. 44, no. 5-6, pp. 483-525, 2007.

[60] A. Kilkkinen, P. Pietinen, T. Klaukka, J. Virtamo, P. Korhonen, and H. Adlercreutz, "Use of oral antimicrobials decreases serum enterolactone concentration," American Journal of Epidemiology, vol. 155, no. 5, pp. 472-477, 2002.

[61] H. A. Ward and G. G. C. Kuhnle, "Phytoestrogen consumption and association with breast, prostate and colorectal cancer in EPIC Norfolk," Archives of Biochemistry and Biophysics, vol. 501, no. 1, pp. 170-175, 2010.

[62] I. E. J. Milder, A. Kuijsten, I. C. W. Arts et al., "Relation between plasma enterodiol and enterolactone and dietary intake of lignans in a dutch endoscopy-based population," Journal of Nutrition, vol. 137, no. 5, pp. 1266-1271, 2007.

[63] M. Cotterchio, B. A. Boucher, N. Kreiger, C. A. Mills, and L. U. Thompson, "Dietary phytoestrogen intake-lignans and isoflavones-and breast cancer risk (Canada)," Cancer Causes and Control, vol. 19, no. 3, pp. 259-272, 2008.

[64] J. E. Cade, V. J. Burley, and D. C. Greenwood, "Dietary fibre and risk of breast cancer in the UK Women's Cohort Study," International Journal of Epidemiology, vol. 36, no. 2, pp. 431-438, 2007.

[65] J. E. Cade, E. F. Taylor, V. J. Burley, and D. C. Greenwood, "Common dietary patterns and risk of breast cancer: analysis from the United Kingdom Women's Cohort Study," Nutrition and Cancer, vol. 62, no. 3, pp. 300-306, 2010.

[66] C. J. Fabian, B. F. Kimler, C. M. Zalles et al., "Reduction in Ki67 in benign breast tissue of high-risk women with the lignan secoisolariciresinol diglycoside," Cancer Prevention Research, vol. 3, no. 10, pp. 1342-1350, 2010.

[67] P. Pietinen, K. Stumpf, S. Männistö, V. Kataja, M. Uusitupa, and H. Adlercreutz, "Serum enterolactone and risk of breast cancer: 
a case-control study in Eastern Finland," Cancer Epidemiology Biomarkers and Prevention, vol. 10, no. 4, pp. 339-344, 2001.

[68] P. Guglielmini, A. Rubagotti, and F. Boccardo, "Serum enterolactone levels and mortality outcome in women with early breast cancer: a retrospective cohort study," Breast Cancer Research and Treatment, vol. 132, no. 2, pp. 661-668, 2012.

[69] A. K. Zaineddin, A. Vrieling, K. Buck et al., "Serum enterolactone and postmenopausal breast cancer risk by estrogen, progesterone and herceptin 2 receptor status," International Journal of Cancer, vol. 130, no. 6, pp. 1401-1410, 2012.

[70] R. G. Ziegler, J. M. Faupel-Badger, L. Y. Sue et al., "A new approach to measuring estrogen exposure and metabolism in epidemiologic studies," Journal of Steroid Biochemistry and Molecular Biology, vol. 121, no. 3-5, pp. 538-545, 2010.

[71] M. S. Roberts, B. M. Magnusson, F. J. Burczynski, and M. Weiss, "Enterohepatic circulation: physiological, pharmacokinetic and clinical implications," Clinical Pharmacokinetics, vol. 41, no. 10, pp. 751-790, 2002.

[72] C. S. Plottel and M. J. Blaser, "Microbiome and malignancy," Cell Host and Microbe, vol. 10, no. 4, pp. 324-335, 2011.

[73] H. Tilg and J. R. Marchesi, "Too much fat for the gut's microbiota," Gut, vol. 61, no. 4, pp. 474-475, 2012.

[74] K. Gloux, O. Berteau, H. El Oumami, F. Béguet, M. Leclerc, and J. Doré, "A metagenomic $\beta$-glucuronidase uncovers a core adaptive function of the human intestinal microbiome," Proceedings of the National Academy of Sciences of the United States of America, vol. 108, no. 1, pp. 4539-4546, 2011.

[75] B. D. Wallace, H. Wang, K. T. Lane et al., "Alleviating cancer drug toxicity by inhibiting a bacterial enzyme," Science, vol. 330, no. 6005 , pp. 831-835, 2010.

[76] C. G. Woolcott, Y. B. Shvetsov, F. Z. Stanczyk et al., "Plasma sex hormone concentrations and breast cancer risk in an ethnically diverse population of postmenopausal women: the multiethnic cohort study," Endocrine-Related Cancer, vol. 17, no. 1, pp. 125134, 2010.

[77] P. J. Turnbaugh, M. Hamady, T. Yatsunenko et al., "A core gut microbiome in obese and lean twins," Nature, vol. 457, no. 7228, pp. 480-484, 2009.

[78] M. Bajzer and R. J. Seeley, "Physiology: obesity and gut flora," Nature, vol. 444, no. 7122, pp. 1009-1010, 2006.

[79] K. Clément, "Bariatric surgery, adipose tissue and gut microbiota," International Journal of Obesity, vol. 35, no. 3, pp. S7-S15, 2011.

[80] D. Compare and G. Nardone, "Contribution of gut microbiota to colonic and extracolonic cancer development," Digestive Diseases, vol. 29, no. 6, pp. 554-561, 2011.

[81] S. Abu-Abid, A. Szold, and J. Klausner, "Obesity and cancer," Journal of Medicine, vol. 33, no. 1-4, pp. 73-86, 2002.

[82] L. Wen, R. E. Ley, P. Y. Volchkov et al., "Innate immunity and intestinal microbiota in the development of Type 1 diabetes," Nature, vol. 455, no. 7216, pp. 1109-1113, 2008.

[83] N. Sudo, Y. Chida, Y. Aiba et al., "Postnatal microbial colonization programs the hypothalamic-pituitary-adrenal system for stress response in mice," Journal of Physiology, vol. 558, no. 1, pp. 263-275, 2004.

[84] T. B. Clarke, K. M. Davis, E. S. Lysenko, A. Y. Zhou, Y. Yu, and J. N. Weiser, "Recognition of peptidoglycan from the microbiota by Nod1 enhances systemic innate immunity," Nature Medicine, vol. 16, no. 2, pp. 228-231, 2010.

[85] B. Wei, G. Wingender, D. Fujiwara et al., "Commensal microbiota and CD8+ T cells shape the formation of invariant NKT cells," Journal of Immunology, vol. 184, no. 3, pp. 1218-1226, 2010.
[86] B. C. Mercier, E. Ventre, M. L. Fogeron et al., "NOD1 cooperates with TLR2 to enhance T cell receptor-mediated activation in CD8 T cells," PLoS ONE, vol. 7, no. 7, Article ID e42170, 2012.

[87] L. Franchi, N. Warner, K. Viani, and G. Nuñez, "Function of Nod-like receptors in microbial recognition and host defense," Immunological Reviews, vol. 227, no. 1, pp. 106-128, 2009.

[88] A. D. Gritzapis, I. F. Voutsas, E. Lekka et al., "Identification of a novel immunogenic HLA-A*0201-binding epitope of HER$2 /$ neu with potent antitumor properties," Journal of Immunology, vol. 181, no. 1, pp. 146-154, 2008.

[89] J. Gui, L. M. Mustachio, D. M. Su, and R. W. Craig, “Thymus size and age-related thymic involution: early programming, sexual dimorphism, progenitors and stroma," Aging and Disease, vol. 3, no. 3, pp. 280-290, 2012.

[90] C. L. Maynard, C. O. Elson, R. D. Hatton, and C. T. Weaver, "Reciprocal interactions of the intestinal microbiota and immune system," Nature, vol. 489, no. 7415, pp. 231-241, 2012.

[91] H. Chung, S. J. Pamp, J. A. Hill et al., "Gut immune maturation depends on colonization with a host-specific microbiota," Cell, vol. 149, no. 7, pp. 1578-1593, 2012.

[92] C. W. Kaplan, X. Ma, A. Paranjpe et al., "Fusobacterium nucleatum outer membrane proteins Fap 2 and RadD induce cell death in human lymphocytes," Infection and Immunity, vol. 78, no. 11, pp. 4773-4778, 2010.

[93] I. I. Ivanov, K. Atarashi, N. Manel et al., "Induction of intestinal Th17 cells by segmented filamentous bacteria," Cell, vol. 139, no. 3, pp. 485-498, 2009.

[94] S. C. Ng, J. L. Benjamin, N. E. McCarthy et al., "Relationship between human intestinal dendritic cells, gut microbiota, and disease activity in Crohn's disease," Inflammatory Bowel Diseases, vol. 17, no. 10, pp. 2027-2037, 2011.

[95] S. Dasgupta and D. L. Kasper, "Novel tools for modulating immune responses in the host-polysaccharides from the capsule of commensal bacteria," Advances in Immunology, vol. 106, pp. 61-91, 2010.

[96] N. Iwabuchi, N. Takahashi, J.-Z. Xiao, K. Miyaji, and K. Iwatsuki, "In vitro Th1 cytokine-independent Th2 suppressive effects of bifidobacteria," Microbiology and Immunology, vol. 51, no. 7, pp. 649-660, 2007.

[97] W. Cozen, A. S. Hamilton, P. Zhao et al., "A protective role for early oral exposures in the etiology of young adult Hodgkin lymphoma," Blood, vol. 114, no. 19, pp. 4014-4020, 2009.

[98] N. C. Reading and D. L. Kasper, “The starting lineup: key microbial players in intestinal immunity and homeostasis," Frontiers in Microbiology, vol. 2, article 148, 2011.

[99] B. Stecher and W.-D. Hardt, "Mechanisms controlling pathogen colonization of the gut," Current Opinion in Microbiology, vol. 14, no. 1, pp. 82-91, 2011.

[100] K. Atarashi, Y. Umesaki, and K. Honda, "Microbiotal influence on T cell subset development," Seminars in Immunology, vol. 23, no. 2, pp. 146-153, 2011.

[101] K. Tsuda, K. Yamanaka, W. Linan et al., "Intratumoral injection of Propionibacterium acnes suppresses malignant melanoma by enhancing Th1 immune responses," PLoS ONE, vol. 6, no. 12, Article ID e29020, 2011.

[102] E. Gounaris, N. R. Blatner, K. Dennis et al., "T-regulatory cells shift from a protective anti-inflammatory to a cancerpromoting proinflammatory phenotype in polyposis," Cancer Research, vol. 69, no. 13, pp. 5490-5497, 2009. 
[103] M. Nanno, M. Morotomi, and H. Takayama, "Mutagenic activation of biliary metabolites of benzo(a)pyrene by $\beta$ glucuronidase-positive bacteria in human faeces," Journal of Medical Microbiology, vol. 22, no. 4, pp. 351-355, 1986.

[104] V. Blasco-Baque, M. Serino, J. N. Vergnes et al., "High-fat diet induces periodontitis in mice through lipopolysaccharides (LPS) receptor signaling: protective action of estrogens," PLoS ONE, vol. 7, no. 11, Article ID e48220.

[105] B. J. Shenker and J. M. DiRienzo, "Suppression of human peripheral blood lymphocytes by Fusobacterium nucleatum," Journal of Immunology, vol. 132, no. 5, pp. 2357-2362, 1984.

[106] W. Chua, K. A. Charles, V. E. Baracos, and S. J. Clarke, "Neutrophil/lymphocyte ratio predicts chemotherapy outcomes in patients with advanced colorectal cancer," British Journal of Cancer, vol. 104, no. 8, pp. 1288-1295, 2011.

[107] M. Kaneko, H. Nozawa, K. Sasaki et al., "Elevated neutrophil to lymphocyte ratio predicts poor prognosis in advanced colorectal cancer patients receiving oxaliplatin-based chemotherapy," Oncology, vol. 82, no. 5, pp. 261-268, 2012.

[108] Y. Kishi, S. Kopetz, Y. S. Chun, M. Palavecino, E. K. Abdalla, and J.-N. Vauthey, "Blood neutrophil-to-lymphocyte ratio predicts survival in patients with colorectal liver metastases treated with systemic chemotherapy," Annals of Surgical Oncology, vol. 16, no. 3, pp. 614-622, 2009.

[109] G. J. Guthrie, K. A. Charles, C. S. Roxburgh, P. G. Horgan, D. C. McMillan, and S. J. Clarke, "The systemic inflammationbased neutrophil-lymphocyte ratio: experience in patients with cancer," Critical Reviews in Oncology/Hematology, 2013.

[110] H. Noh, M. Eomm, and A. Han, "Usefulness of pretreatment neutrophil to lymphocyte ratio in predicting disease-specific survival in breast cancer patients," Journal of Breast Cancer, vol. 16, no. 1, pp. 55-59, 2013.

[111] B. Azab, V. R. Bhatt, J. Phookan et al., "Usefulness of the neutrophil-to-lymphocyte ratio in predicting short- and longterm mortality in breast cancer patients," Annals of Surgical Oncology, vol. 19, no. 1, pp. 217-224, 2012.

[112] S. Loi, N. Sirtaine, F. Piette et al., "Prognostic and predictive value of tumor-infiltrating lymphocytes in a phase III randomized adjuvant breast cancer trial in node-positive breast cancer comparing the addition of docetaxel to doxorubicin with doxorubicin-based chemotherapy: BIG 02-98," Journal of Clinical Oncology, vol. 31, no. 7, pp. 860-867, 2013.

[113] L. J. Standish, E. S. Sweet, J. Novack et al., "Breast cancer and the immune system," Journal of the Society for Integrative Oncology, vol. 6, no. 4, pp. 158-168, 2008.

[114] S. M. A. Mahmoud, E. C. Paish, D. G. Powe et al., "Tumorinfiltrating CD8+ lymphocytes predict clinical outcome in breast cancer," Journal of Clinical Oncology, vol. 29, no. 15, pp. 1949-1955, 2011.

[115] N. R. West, S. E. Kost, S. D. Martin et al., "Tumour-infiltrating FOXP3 $^{+}$lymphocytes are associated with cytotoxic immune responses and good clinical outcome in oestrogen receptornegative breast cancer," British Journal of Cancer, vol. 108, no. 1, pp. 155-162, 2013.

[116] I. Soerjomataram, J. Lortet-Tieulent, D. M. Parkin et al., "Global burden of cancer in 2008: a systematic analysis of disabilityadjusted life-years in 12 world regions," The Lancet, vol. 380, no. 9856, pp. 1840-1850, 2012.

[117] K. Nasseri, P. K. Mills, and M. Allan, "Cancer incidence in the Middle Eastern population of California, 1988-2004," Asian Pacific Journal of Cancer Prevention, vol. 8, no. 3, pp. 405-411, 2007.
[118] B. D. Muegge, J. Kuczynski, D. Knights et al., "Diet drives convergence in gut microbiome functions across mammalian phylogeny and within humans," Science, vol. 332, no. 6032, pp. 970-974, 2011. 


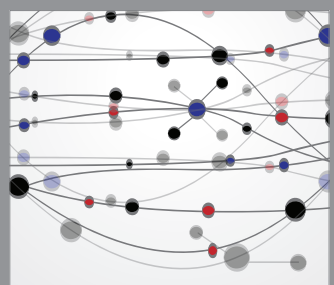

The Scientific World Journal
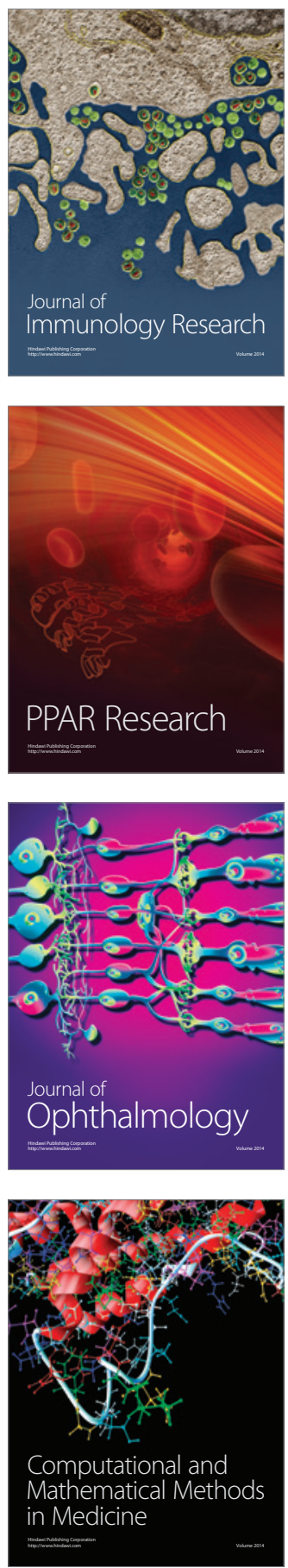

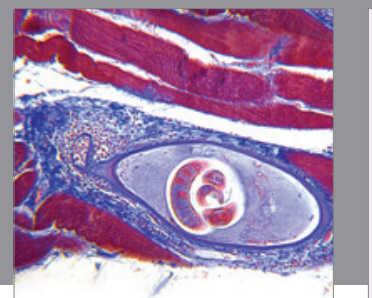

Gastroenterology

Research and Practice
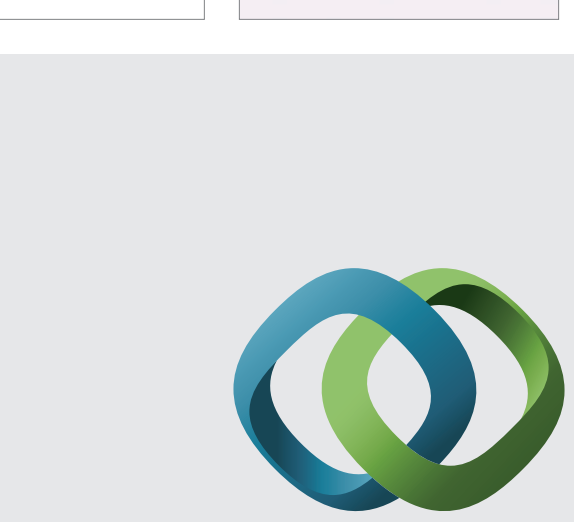

\section{Hindawi}

Submit your manuscripts at

http://www.hindawi.com
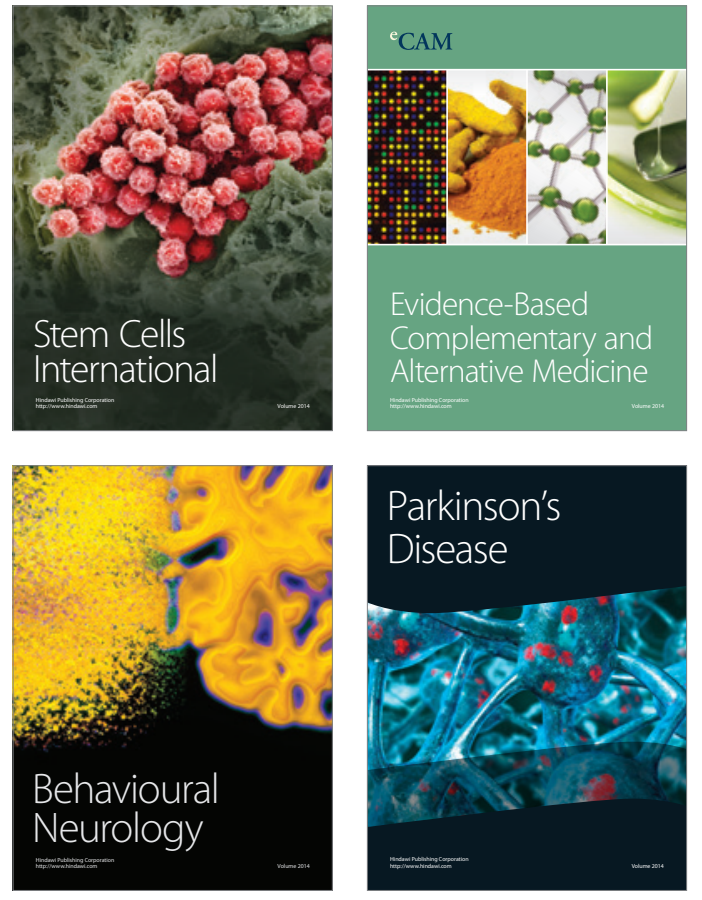
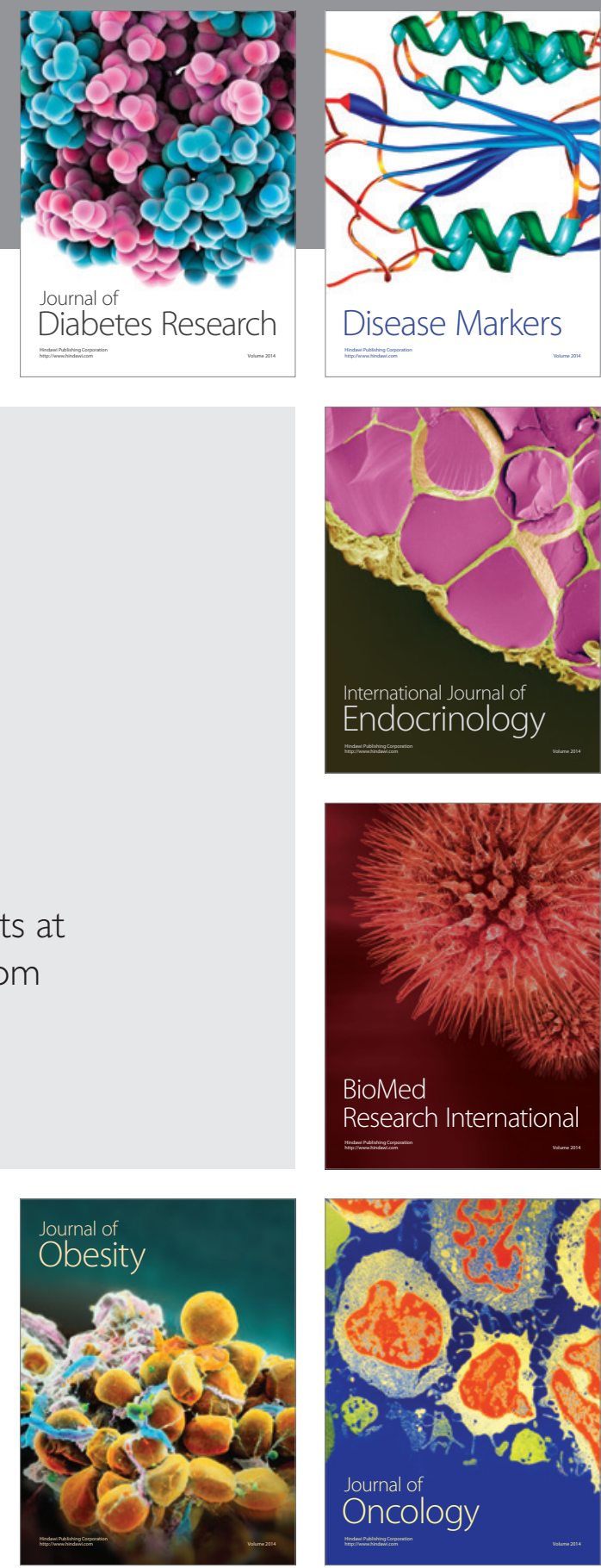

Disease Markers
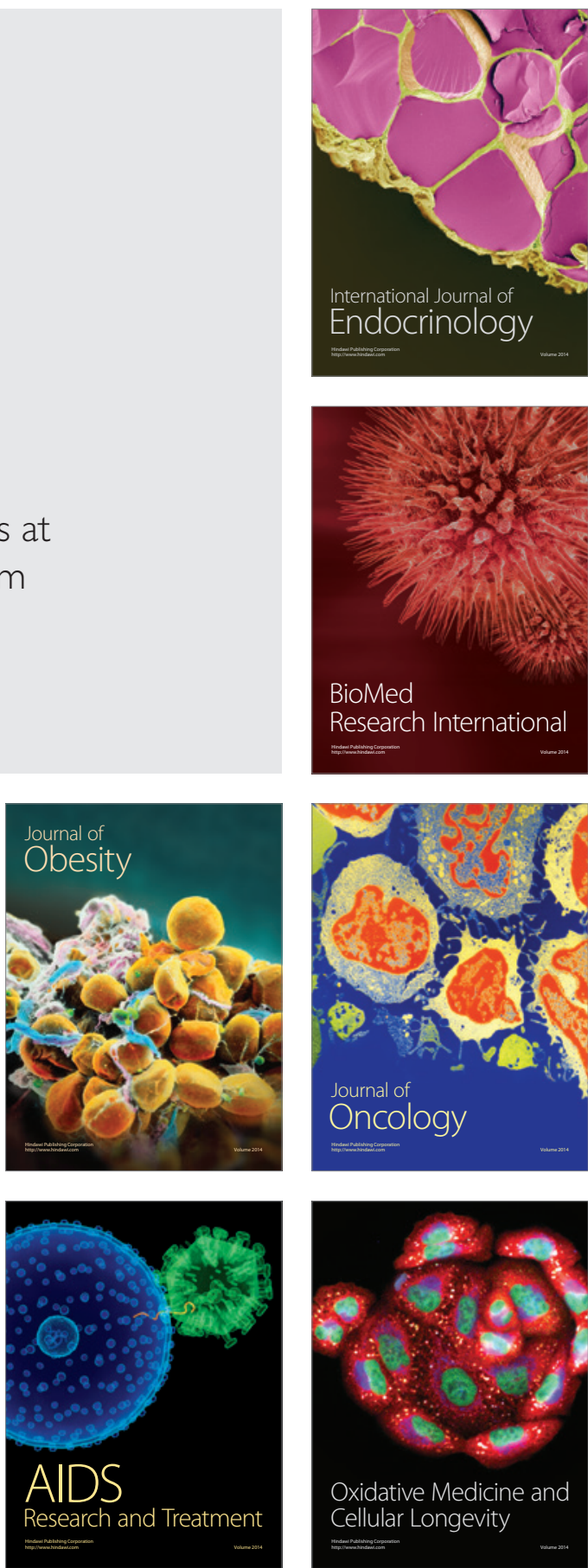